\title{
Sobre la libertad. Un contrapunto entre Hegel y Marx
}

\author{
About freedom. A counterpoint between Hegel and Marx
}

Patricia Lambruschini*

Resumen: El artículo realiza una comparación entre las concepciones de la libertad de Hegel y Marx, indagando continuidades y rupturas entre ambas. Para ello, retoma sobre todo los Fundamentos de la filosofía del derecho de Hegel y algunos escritos juveniles de Marx donde critica y se separa de la corriente hegeliana y neohegeliana. El análisis de dichas concepciones de la libertad tiene en cuenta especialmente la perspectiva teórica de cada autor, cuál es el ámbito que considera apropiado para su realización y para conciliar los intereses individuales y comunes, y cómo entiende su desenvolvimiento a lo largo de la historia.

Palabras clave: Hegel, Marx, libertad, Estado, historia

Abstract: The article makes a comparison between the conceptions of freedom of Hegel and Marx, inquiring continuities and ruptures between them. For that, it retakes above all the Elements of the philosophy of right of Hegel and some Marx's youthful writings where he criticizes and departs from the hegelian and neo-hegelian current. The analysis of these conceptions of freedom takes into account especially the theoretical perspective of each author, what is the scope he considers appropriate for its implementation and to reconcile individual and common interests, and how he understands its development along the history.

Keywords: Hegel, Marx, freedom, State, history

Recibido: 6 diciembre 2016

Aceptado: 30 marzo 2017

\footnotetext{
* Argentina. Licenciada y Profesora de Sociología por la Universidad de Buenos Aires. Becaria doctoral del Consejo Nacional de Investigaciones Científicas y Técnicas (CONICET). Docente en la carrera de Ciencias de la Educación de la Universidad Nacional de Entre Ríos y en la carrera de Sociología de la Universidad de Buenos Aires. Correo electrónico: plambrus84@ gmail.com
} 


\section{Introducción}

Si fuese posible sintetizar cuál fue el tema cardinal del pensamiento de Hegel y Marx, habría poco lugar a vacilaciones. Los dos se abocaron principalmente al problema de la libertad y las formas de organización social que permiten su plena realización, revelándose de este modo como firmes herederos de la Ilustración.

El escenario de la modernidad en el que escribieron, donde el capitalismo y el progreso de la división del trabajo llevaron al surgimiento del individuo y a una creciente hegemonía de los intereses privados, planteó desafíos novedosos que ambos buscaron resolver: ¿cómo contemplar el desenvolvimiento de la individualidad pero superando el desgarramiento, el egoísmo y los antagonismos presentes en la sociedad civil?; ¿cómo conciliar los intereses particulares de las personas con los intereses universales de la comunidad?

Como se sabe, Marx fue un receptor y un crítico de Hegel. Su pensamiento expresa un pasaje desde el hegelianismo de izquierda hacia el socialismo revolucionario, y es precisamente en su concepción de la libertad donde se evidencia su herencia y también su mayor ruptura con el filósofo. Aunque en sus escritos de juventud Marx polemiza permanentemente con la filosofía del derecho hegeliana, se le ha prestado poca atención a los aspectos en que su idea de la libertad implica una continuidad o bien un quiebre y superación de la de Hegel.

Así pues, el presente trabajo se propone realizar una comparación entre las concepciones de la libertad de Hegel y Marx, indagando puntos de encuentro y desencuentro entre ambas perspectivas. A tal fin, se retoman principalmente los Fundamentos de la filosofía del derecho de Hegel y algunos escritos juveniles de Marx -en particular, La ideología alemana- donde realiza la crítica y se separa de la corriente hegeliana y neohegeliana. La selección de estos textos responde al interés comparativo que motiva estas páginas, pero también a la convicción de que en ellos se concentran los rasgos primordiales (aunque sin duda, no los únicos) de sus respectivas ideas sobre la libertad.

\section{Coincidencias en el abordaje de la libertad}

En el abordaje que Hegel y Marx realizan del problema de la libertad se pueden advertir varios puntos en común que merecen ser destacados. Aquí se mencionarán sólo algunos especialmente importantes, sin pretender agotar esta cuestión.

En ambos autores se expresa un rechazo del atomismo propio de los contractualistas, que pensaban la sociedad y el Estado como emergentes de un acuerdo voluntario entre individuos aislados unos de otros; ${ }^{1}$ y también del liberalismo de los economistas políticos que explicaban el bien común como el resultado natural del libre

\footnotetext{
${ }^{1}$ Norberto Bobbio realiza un buen análisis sobre vínculo entre Hegel y el contractualismo y sus planteos son, en parte, también extensibles a Marx. Norberto Bobbio, "Hegel y el iusnaturalismo", VV. AA., Estudios sobre la filosofía del derecho de Hegel, Madrid, Centro de Estudios Constitucionales, 1989, 377 - 406.
} 
juego de los egoísmos individuales en la esfera económica. Frente a estos planteos, Hegel y Marx parecen recuperar las ideas de Aristóteles $^{2}$ y de Rousseau ${ }^{3}$ : del primero, su concepción del hombre como zoon politikón y de la polis como una totalidad orgánica anterior a las partes y, del segundo, su concepción de la "voluntad general" como una realidad sustancialmente distinta que la mera sumatoria de voluntades individuales o la voluntad de la mayoría. Así, tanto Hegel como Marx entienden al individuo como un ser esencialmente social, que se desarrolla viviendo con otros y que sólo puede realizarse plenamente en el marco de la intersubjetividad. ${ }^{4}$ La vida en común es una realidad existente en sí misma y una premisa para el desenvolvimiento individual. Para ellos, el interés general es superior e irreductible a los intereses particulares vigentes en la sociedad civil y la libertad de la comunidad es una precondición para la libertad del individuo.

A su vez, sus respectivas ideas de la libertad incluyen y sintetizan de manera superadora otras formas previas de concebirla. Por un lado, abarcan la libertad "liberal" que plantea que nadie está obligado a hacer lo que la ley no manda ni impedido de hacer lo que ella no prohíbe explícitamente por lo que, salvo en esas excepciones, las personas son libres de actuar según su voluntad. Se trata de una libertad "negativa", cuyo su objetivo fundamental es proteger al individuo de los potenciales abusos del poder, y especialmente del poder del Estado. Como se sabe, Hobbes ${ }^{5}$ fue el teórico fundacional de esta libertad entendida como no impedimento y Locke fue una de sus expresiones más radicalizadas. En efecto, Locke fue uno de los primeros en plantear la apropiación del propio cuerpo como una precondición de la libertad individual -quitando con ello toda legitimidad a la esclavitud y la servidumbre-; en considerar la propiedad resultante del propio trabajo como una manifestación de aquélla; y en justificar filosóficamente el derecho de resistencia a la opresión y a la insurrección. ${ }^{6}$ Por otro lado, también recuperan la libertad entendida como "autonomía" que plantea que obedeciendo la ley -que es esencialmente universal y racional-, el individuo se obedece a sí mismo, pues obedece a su propia razón. Se trata en este caso de una libertad "positiva", que alcanza sus expresiones más acabadas en la "voluntad general" de Rousseau, donde los individuos enajenan sus derechos en la comunidad al fundar el Estado y luego actúan obedeciendo las leyes que ellos se han dado como miembros de éste; ${ }^{7}$ y en el "imperativo categórico" de Kant, donde los sujetos obran siguiendo los dictados de su conciencia moral y sin tener en cuenta ninguna otra motivación más que el deber. ${ }^{8}$ Las concepciones hegeliana y marxista de la libertad implican una recepción de estas formas negativa y positiva de entenderla y una reelaboración todavía más acabada.

${ }^{2}$ Aristóteles, Política, México, Universidad Nacional Autónoma de México, 1963.

${ }^{3}$ Jean-Jacques Rousseau, El contrato social, Madrid, Alianza, 2012 [1762].

${ }^{4}$ Rubén Dri, La rosa en la cruz. La filosofía política hegeliana, Buenos Aires, Biblos, 2009, 105.

${ }^{5}$ Thomas Hobbes, Elementos filosóficos. Del ciudadano, Buenos Aires, Hydra, 2010 [1642].

${ }^{6}$ John Locke, Ensayo sobre el gobierno civil, Buenos Aires, Universidad Nacional de Quilmes - Prometeo, 2005 [1690].

${ }^{7}$ Rousseau, op. cit.

${ }^{8}$ Immanuel Kant, Fundamentación para una metafísica de las costumbres, Madrid, Alianza, 2002 [1785].

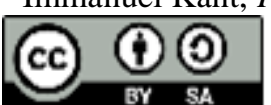


A contramano de la antropología hobbesiana que naturalizaba los vicios y el antagonismo de unos hombres contra otros, Hegel y Marx los interpretan como producto de las condiciones históricas, los valores, las costumbres y las creencias propias de la sociedad burguesa y sus concepciones de la libertad expresan un intento de resolver este desgarramiento, en el marco de una comunidad donde la realización de cada uno se complementa y amplía con la de los demás. Alcanzar la auténtica libertad supone para ambos un proceso de lucha, de toma de conciencia y de mutuo reconocimiento entre los seres humanos, en el que resulta primordial el rol del trabajo y de la clase social dedicada al trabajo.

Finalmente, tanto Hegel como Marx entienden el desenvolvimiento de la libertad individual y colectiva como el producto histórico de un desarrollo que reconoce distintos momentos y, en definitiva, para ambos autores la historia de la humanidad no es otra cosa que la historia de su emancipación.

En todas estas coincidencias sobre el problema de la libertad, el planteo marxista puede ser considerado como heredero y continuador del planteo hegeliano. Sin embargo, las diferencias entre ellos también son sustanciales, pues la distancia que separa a Hegel de Marx es la que existe entre la filosofía idealista y el materialismo histórico; entre la revolución burguesa y la revolución proletaria; y entre el Estado de derecho y la sociedad comunista. Por lo tanto, es necesario atender a estos contrastes al interpretar sus ideas sobre dicho problema.

En este sentido, a continuación se analizan ambas concepciones de la libertad teniendo en cuenta la perspectiva teórica de la que parten, cuál es el ámbito que consideran apropiado para su realización y para conciliar los intereses individuales y comunes, y cómo entienden su desenvolvimiento a lo largo de la historia.

\section{La libertad según Hegel}

\section{El idealismo absoluto}

Como se sabe, Hegel forma parte de la corriente filosófica idealista heredera de Kant, que plantea que los objetos de conocimiento y de pensamiento no tienen una existencia independiente del sujeto que los aprehende y son construidos por éste. Hegel es, de hecho, la expresión más radical de esta corriente pues le otorga una primacía absoluta al sujeto. En efecto, según sostiene en la Fenomenología del Espíritu, para toda la filosofía anterior el "ser" de algo era sinónimo de "sustancia", de una supuesta esencia originaria e inmediata, pero lo que corresponde plantear es que la sustancia es en verdad "sujeto" y, en cuanto tal, es "el movimiento del ponerse a sí misma o la mediación de su devenir otro consigo misma". Para el filósofo no existe "la cosa-en-sí" y tampoco la distinción entre una realidad fenoménica y una nouménica. Lo que algo "es", siempre lo es en relación a algo

${ }^{9}$ Georg Wilhelm Friedrich Hegel, Fenomenología del espíritu, México, Fondo de Cultura Económica, 1973 [1807], 16. 
exterior a él, siempre lo es en relación a la totalidad. El sujeto es siempre "sujeto-objeto", y sólo es "real" en la medida en que funcione como "sí mismo" a través del conjunto de relaciones contradictorias que constituyen su existencia. El "ser" coincide con su aparecer, es su manifestación activa y, en consecuencia, debe ser aprehendido en su continuo devenir. Por este motivo, la filosofía hegeliana se caracteriza por tener conceptos vivos y dinámicos y se vale del método dialéctico para indagar la realidad en su movimiento. Como plantea Rubén Dri, "es la realidad la que dicta el método, porque éste no es otra cosa que su mismo movimiento". "Lo que Hegel denomina "idea" o "concepto" es al mismo tiempo el fundamento y la finalidad de todo lo que se expresa en la realidad, de manera que en su perspectiva fílosófica, el "ser" y el "deber-ser" coinciden en un mismo desarrollo. Lo único real y verdadero es el todo, el espíritu absoluto, pero éste es esencialmente "resultado" y sólo al final es lo que es efectivamente. ${ }^{11}$ La totalidad de lo existente -que la filosofía pretende captar- son distintas manifestaciones del espíritu (de carácter teórico, práctico o productivo), en distintos momentos de su desarrollo (“en-sî́, "para-sí” y “en-sí-para-sî”). Resulta primordial entonces que el sujeto se vuelva reflexivo sobre sí mismo, que devenga autoconsciente y comprenda que el mundo de los hombres es producto de su propia creación.

Herbert Marcuse destaca el potencial crítico de esta idea de la realidad como una realización del sujeto, que está estrechamente vinculada a la concepción hegeliana de la "razón" como una fuerza histórica objetiva. Heredero de la Revolución Francesa, Hegel considera que hay que adecuar la realidad a las normas de la razón y configurar las formas de organización social y política de acuerdo a lo que el hombre piensa que es justo y verdadero. Su concepto de razón, se opone a toda aceptación pasiva de las condiciones existentes y contempla "aunque bajo una forma idealista, los esfuerzos materiales por un orden de vida libre y racional". 12

El sistema hegeliano abarca las tres partes integrantes de la dialéctica: el universal abstracto, desarrollado en la Lógica; el particular, en la Filosofía de la Naturaleza; y el universal concreto, en la Filosofía del espíritu. Esta última se divide, a su vez, en la filosofía del espíritu subjetivo, del espíritu objetivo y del espíritu absoluto.

\section{La filosofía del derecho o el devenir de la idea de libertad}

En Fundamentos de la filosofía del derecho, Hegel desarrolla el momento del espíritu objetivo, que se despliega en el "derecho abstracto", la "moralidad" y la "eticidad", y que constituye la base para que se desenvuelva plenamente el espíritu absoluto conformado por el "arte", la "religión" y la "filosofía". "3 Escrita en el contexto reaccionario de la

\footnotetext{
${ }^{10}$ Dri, op. cit., 96.

${ }^{11}$ Hegel, op. cit., 16.

${ }^{12}$ Herbert Marcuse, Razón y revolución. Hegel y el surgimiento de la teoría social, Barcelona, Altaza, 1999, 11.

${ }^{13}$ En este punto, hay que destacar que la filosofía del derecho finaliza allí donde comienza la filosofía de la historia universal.
} 
Restauración, ${ }^{14}$ esta obra resulta fundamental no sólo para entender la concepción hegeliana de la libertad, sino también aquellos aspectos en los que Marx se separa de ésta.

En los Fundamentos... Hegel polemiza con las corrientes que pretendían excluir al Estado y al mundo ético del terreno del conocimiento y de la razón, abandonándolos a la contingencia, a la arbitrariedad y a la opinión individual. Por el contrario, justifica su estudio por parte de la filosofía, en tanto ciencia que estudia "lo que es" y "lo racional". El mundo ético y el Estado son reales, existen objetivamente en la vida colectiva presente de los hombres, y son racionales de un modo eminente, porque en sus leyes la razón no sólo se realiza, sino que llega a saber que se realiza. ${ }^{15}$

"La ciencia filosófica del derecho tiene por objeto la idea del derecho, el concepto del derecho y su realización" $" 16$ y la idea del derecho no es otra que la libertad, la cual debe ser conocida en su concepto y en la existencia que adopta su concepto. ${ }^{17}$ Sin embargo, las diversas configuraciones particulares que la idea asume al realizarse históricamente, no son objeto de la filosofía.

El ámbito del derecho es en general lo espiritual y su lugar más exacto y su punto de partida la voluntad, que es libre, de tal modo que la libertad constituye su sustancia y determinación, y el sistema del derecho es el reino de la libertad realizada, el mundo del espíritu producido a partir de él mismo como una segunda naturaleza. ${ }^{18}$

Así, a contramano del positivismo que naturaliza la existencia del derecho y del Estado independizándolos de las condiciones históricas y de los sujetos que los han creado, Hegel remarca de entrada su carácter "espiritual", es decir, esencialmente humano e intersubjetivo. ${ }^{19}$ El punto de partida del derecho es la "voluntad", el sujeto libre, y la realización de la libertad constituye su sustancia, su determinación y su finalidad. El Estado es la forma culminante de la vida colectiva de los hombres, donde se moldea su segunda naturaleza propiamente ética, elevándolos por encima de los impulsos y necesidades inmediatas. Por este motivo, el sistema del derecho constituye para el filósofo "el reino de la libertad realizada".

14 Félix Duque realiza una interesante reconstrucción del contexto histórico de la Restauración y su vinculación, problemática y tantas veces mal interpretada, con la escuela hegeliana. Félix Duque, La Restauración. La escuela hegeliana y sus adversarios, Madrid, Akal, 1999.

${ }^{15}$ Eric Weil, Hegel y el Estado, Córdoba, Nagelkop, 1970, 35.

${ }^{16}$ Georg Wilhelm Friedrich Hegel, Fundamentos de la filosofía del derecho, Madrid, Libertarias/Prodhufi, 1993 [1821], 66, §1.

${ }^{17}$ Como aclara Julio De Zan, "la idea del derecho no es ninguna abstracción, sino que es la realidad misma de la libertad concreta, la libertad realizada, en cuanto concepto existente que se ha dado una configuración, o que ha configurado el mundo conforme a su concepto. Esta configuración, que no existe solamente como concepto, es el otro momento esencial de la idea, el momento de su realidad, que es el punto de partida para la comprensión del concepto de la cosa". Julio De Zan, "Para leer la filosofía del derecho de Hegel", Tópicos, $18,2009,4$.

${ }^{18}$ Hegel, op.cit., $96, \S 4$.

${ }^{19}$ Dri, op. cit., 104. 
A lo largo de los Fundamentos... Hegel reseña el devenir lógico de la idea de libertad que se ha vuelto objetiva y real: en un recorrido que comienza en la propiedad y termina en el Estado moderno, describe la libertad que se ha realizado en las relaciones entre los hombres, en los valores, en las costumbres, en las instituciones sociales, en las leyes, todas las cuales son consideradas como objetivaciones del espíritu. Los distintos momentos de este proceso expresan, a su vez, distintos grados de desarrollo del sujeto libre, de la voluntad en-sí y para-sí.

El primer momento es la esfera del "derecho abstracto" y de la voluntad considerada de manera inmediata, en su pura indeterminación y reflexión sobre sí misma, donde quedan disueltos toda limitación y todo contenido particular. El sujeto del derecho es la "persona" individual, cuya existencia como sujeto libre se manifiesta en su relación con una cosa externa inmediata: la propiedad. Este momento es el universal abstracto en el devenir de la libertad, es la libertad entendida de manera negativa y el nivel más básico en la realización del sujeto, aunque indispensable para su desarrollo. Hegel realiza aquí un planteo análogo al de Locke, que concibe la propiedad como una exteriorización de la libertad, como su expresión más inmediata y elemental, primero como apropiación del propio cuerpo y, luego, como apropiación de algo exterior mediante el trabajo. ${ }^{20}$ La dialéctica del derecho abstracto se despliega en la "propiedad", el "contrato" y la "injusticia". En el ámbito del derecho, las personas sólo tienen existencia y se relacionan entre sí en tanto propietarios y establecen contratos para moderar sus enfrentamientos e intercambiar sus respectivas propiedades. Sin embargo, los contratos no siempre se respetan y tienden romperse, conduciendo de este modo al surgimiento del delito y la injusticia. Esto hace necesario el pasaje a una segunda esfera. ${ }^{21}$

La "moralidad" es el momento de la particularidad, donde la voluntad se determina como "individualidad subjetiva" frente a lo universal. El sujeto sólo se constituye como individuo particularizándose, limitándose, dotándose de ciertos contenidos de carácter material y espiritual que lo distinguen de los demás. Aunque el individuo ya existía en las sociedades pre-modernas, se encontraba fuertemente absorbido por la universalidad y ésta le impedía afirmarse como tal. Sólo durante la modernidad fue posible un amplio desarrollo de la diferenciación social y el surgimiento efectivo del individuo; y sólo en esa época se generó un espacio institucional propicio para el desenvolvimiento individual, como es la sociedad civil. ${ }^{22}$ La moralidad es la manera en que el particular se relaciona con los valores universales de la sociedad en la que vive y se expresa en sus acciones morales. Sus tres momentos son: "el propósito y la responsabilidad", "la intención y el bienestar", y "el bien y la conciencia moral". Hegel describe aquí una libertad similar al imperativo categórico kantiano, en la que el individuo actúa de acuerdo a fines universales, persiguiendo la realización del bien y de la justicia.

\footnotetext{
${ }^{20}$ Hegel es sumamente lúcido al señalar que la libertad encuentra un fundamento material en la propiedad y el menoscabo que implica carecer de esta última. En este sentido, es heredero de la idea republicana según la cual ser libre significa no tener un amo y no depender de otro.

${ }^{21}$ Dri, op. cit., 114.

${ }^{22}$ Ibid., 110.
} 
Sin embargo, para el filósofo estos dos momentos son todavía abstractos, son momentos no verdaderos y del entendimiento. En efecto, "el sujeto nunca es meramente universal abstracto. Tampoco particular. Siempre es universal concreto, pero éste sólo se puede pensar en la contradicción entre universal y particular". ${ }^{23}$ La libertad real, la que se manifiesta de manera concreta en el seno de la comunidad, en el "espíritu del pueblo", y que contempla la afirmación del individuo en el marco de dicha contradicción, es la que describe en el tercer momento del espíritu objetivo.

La eticidad es la idea de la libertad en cuanto bien viviente que tiene en la autoconciencia su saber, su querer y -por medio de su actuar- su realidad, así como este actuar tiene en el ser ético su base en sí y para sí y su fin motor, el concepto de libertad que se ha convertido en mundo existente y en naturaleza de la autoconciencia. ${ }^{24}$

La "eticidad" es el mundo ético, la vida intersubjetiva de los hombres, donde se realiza verdaderamente la idea de libertad y se manifiesta como mundo existente. Es la libertad como realidad viviente, que surge de las acciones e interacciones humanas en continuo movimiento y transformación, y que tiene en el propio desenvolvimiento de la eticidad su origen y su finalidad. Es la libertad que se desarrolla, no de manera solipsista, sino en el marco de la vida ética colectiva que enriquece a los individuos y les permite su realización como sujetos libres. Y cuando éstos descubren que aquí radica su fundamento y su razón de ser, la libertad alcanza su saber y su querer, es decir, deviene autoconsciente.

La dialéctica de la eticidad se despliega en la "familia", la "sociedad civil" y el "Estado". 25 La "familia" es el universal abstracto, donde el espíritu ético se encuentra todavía impregnado de naturaleza. La unidad familiar se basa principalmente en la sensibilidad y en el amor que existe entre sus miembros. "El individuo, en el sentimiento del amor confiado, lleva una existencia concreta que es [...] libre porque es existencia en el consentimiento". 26 Sin embargo, la familia es una comunidad inmediata que abraza al individuo pero dificulta su particularización y solamente al independizarse de ella, sus integrantes devienen sujetos de derechos.

El segundo momento es la "sociedad civil", conformada por un conjunto de personas independientes que están unidas formalmente por medio del sistema de trabajo y de satisfacción de las necesidades; y también por medio de la constitución jurídica que garantiza la propiedad, los derechos de las personas y un orden externo para sus intereses particulares y comunes. Hegel retoma aquí la noción rousseauniana de bürgerliche Gesellschaft y la utiliza para referirse a las características económico-sociales de la

\footnotetext{
${ }^{23}$ Ibid., 111.

${ }^{24}$ Hegel, op. cit., 530, §142.

${ }^{25}$ La presente consideración de la dialéctica de la eticidad se realiza en función del problema de la libertad, que es el tema de este trabajo. En consecuencia, sólo se hará referencia a los tres grandes momentos de dicha dialéctica, sin detenernos en los momentos internos de cada uno de ellos.

${ }^{26}$ Weil, op. cit., 56.
} 
sociedad moderna, ubicándola como el momento de la escisión y de la particularidad en el movimiento dialéctico que expone. En efecto, en la sociedad civil los individuos se rigen por sus fines particulares y las relaciones con los demás se les presentan sólo como un medio necesario para llevarlos adelante porque, aunque cada uno actúa persiguiendo sus intereses egoístas, existe una mutua dependencia para garantizar las propias necesidades y el propio bienestar material y espiritual, debido a la división del trabajo. Para Hegel, lo ético se halla aquí perdido en sus extremos, porque la particularidad se encuentra enfocada sobre sí misma y separada de la universalidad, actuando como persona privada en función de su libre albedrío y de sus impulsos y necesidades inmediatas. Por eso en este momento (que corresponde al entendimiento), el Estado es visto por los sujetos como una realidad exterior que se les impone y les impide desarrollarse libremente. En este marco, la sociedad civil ofrece "el espectáculo del vicio, de la miseria y de la corrupción a la vez físico-social y ética". ${ }^{27}$ Según Hegel, para que el individuo se eleve desde este actuar arbitrario y sometido a la necesidad natural, hacia la libertad y la universalidad, es necesario un dura tarea de formación (Bildung) que cultive la subjetividad, y que constituye por eso una auténtica liberación. Como plantea en la dialéctica del señor y el siervo desarrollada en la Fenomenología del espíritu, en dicha formación juega un rol fundamental el proceso de trabajo y la lucha por el reconocimiento entablada entre dominantes y dominados, en donde estos últimos están en mejores condiciones de emanciparse a sí mismos y también a los primeros de su relación intersubjetiva cosificada.

\section{El Estado como realización de la libertad y de la razón}

El tercer momento de la eticidad es el "Estado" y constituye para Hegel el ámbito que permite el pleno desenvolvimiento de la libertad y del sujeto. Como señala Norberto Bobbio, en este punto el filósofo se revela no sólo como heredero sino como la expresión más acabada de la convicción del iusnaturalismo -y en general, de la teoría política anterior-, de que el Estado es la forma más elevada o menos imperfecta de convivencia humana y el terreno que permite al hombre llevar una vida conforme a la razón. ${ }^{28}$ En efecto, para Hegel

El Estado es la realidad de la idea ética, el espíritu ético en cuanto voluntad patente, ostensible a sí misma, sustancial, que se piensa y sabe y cumple aquello que sabe y en la medida en lo sabe. En la costumbre tiene su existencia inmediata, y en la autoconsciencia del individuo, en su saber y actividad, tiene su existencia mediada, así como esta autoconsciencia por el carácter- tiene en él cual esencia suya, finalidad y producto de su actividad, su libertad sustancial. ${ }^{29}$

\footnotetext{
${ }^{27}$ Hegel, op. cit., 620, §185.

${ }^{28}$ Bobbio, op. cit., 394.

${ }^{29}$ Hegel, op. cit., 678, §257. 
En cuanto realidad de la voluntad sustancial, realidad que ésta tiene en la autoconsciencia particular elevada a su universalidad, el Estado es lo racional en sí y para sí. Esta unidad sustancial es autofinalidad absoluta, inmóvil, donde la libertad llega a su derecho supremo, así como esta finalidad última tiene el derecho supremo frente a los individuos, cuyo deber supremo consiste en ser miembros del Estado. ${ }^{30}$

Considerada abstractamente, la racionalidad consiste en general en la unidad compenetradora de la universalidad y de la individualidad, y aquí, -en concreto, en cuanto al contenido- en la unidad de la libertad objetiva (es decir, de la voluntad sustancial universal) y la libertad subjetiva, en cuanto libertad del saber individual y de la voluntad que busca su finalidad particular y por ello -en cuanto a la forma- en un actuar que se determina según leyes y principios pensados, es decir, universales. ${ }^{31}$

La idea ética o la libertad, que está presente en la familia y en la sociedad civil sólo como entendimiento, se expresa en el Estado como pensamiento y alcanza en éste su auténtica realidad (Wirklichkeit) y autoconciencia. El Estado existe de manera inmediata en las costumbres, en los valores y en los sentimientos del pueblo (por ejemplo, el patriotismo), en los cuales hunde sus raíces. Y existe de manera mediata en la autoconciencia del individuo, en su acción y su saber elevados al plano universal, mediante los cuales deja de ser una persona puramente privada para convertirse en ciudadano. A su vez, el individuo/ciudadano posee en el Estado su "libertad sustancial", que constituye para Hegel la esencia, la finalidad y el resultado de la actividad estatal.

El Estado es la realización concreta de la razón y de la libertad, que adquieren en éste su valor supremo. Es la realidad de la "voluntad sustancial" y no de una libertad entendida de manera atomista, pues sólo en el marco de un pueblo libre puede tener el individuo su propia libertad, la cual se potencia y amplía con la libertad de los demás. Y es "lo racional en sí y para sî", porque encarna fines universales de manera consciente y porque realiza la unidad entre el universal y el particular, entre la libertad objetiva y la subjetiva.

El Estado es la forma más desarrollada de la vida ética, que eleva al sujeto por encima de los vínculos puramente naturales o necesarios y permite el pleno desenvolvimiento de su particularidad. En consecuencia, es el fin último y superior al que debe aspirar el individuo, y no hay mayor deber para éste que ser ciudadano del Estado y actuar conforme a sus leyes, porque sólo llevando una vida universal alcanza el individuo su libertad subjetiva y su plena realización como sujeto. Como se puede advertir, este planteo hegeliano está fuertemente inspirado en la concepción rousseauniana de la "voluntad general" y de la "autonomía"; la diferencia reside en que para Hegel el Estado no resulta del acuerdo voluntario de los individuos en el "contrato social", sino que es una realidad existente en sí misma y una totalidad anterior a éstos: es la "sustancia ética".

\footnotetext{
${ }^{30}$ Ibid., 678-679, §258.

${ }^{31}$ Ibid., 679-680, §258/Obs. 3. 
Pero la idea de libertad que se realiza en el Estado es todavía más perfecta que la autonomía al estilo rousseauniano, porque ella ha devenido autoconsciente. La "libertad-conscientede-sî" (que Hegel esboza en sus Fundamentos... y desarrolla más específicamente en sus Lecciones de filosofía de la historia universal) es la libertad que se ha vuelto reflexiva sobre sí misma y se trata para el filósofo de la verdadera libertad. Es la libertad que se sabe libre y se quiere libre: la que se autocomprende como una conquista histórica, como el resultado de un proceso de liberación, y que quiere ser libre precisamente porque sabe lo que significa no serlo. Una libertad que se ignora a sí misma como libertad, esto es, como el producto de la lucha social e histórica de los hombres por emanciparse, no es una auténtica libertad.

Así pues, la filosofía del derecho que describe la realización de la idea de libertad en el Estado, finaliza y empalma con la filosofía de la historia universal, que constituye para Hegel la historia de la liberación de la humanidad.

\section{La historia universal de la libertad}

En la filosofía de la historia hegeliana la protagonista por excelencia es la idea del Estado y el desarrollo histórico universal adquiere la forma de una sucesión lógica de distintas configuraciones estatales, puesto que la naturaleza de la libertad se identifica para el filósofo con la naturaleza del Estado.

En efecto, como sostiene en los Fundamentos..., la historia universal es el "elemento" en el que se realiza el espíritu universal; es la realidad espiritual en toda su extensión y su proceso de autoconocimiento y liberación. La historia universal es también un tribunal que juzga y decide, y frente al cual los pueblos particulares existen sólo como manifestaciones "ideales". Ella no procede irracional y ciegamente, sino que está gobernada racionalmente por la razón o el espíritu universal y se desenvuelve de manera teleológica y progresiva, representando "el despliegue necesario a partir sólo del concepto de su libertad, de los momentos de la razón y por ende de su autoconciencia y de su libertad: la exposición y realización del espíritu universal". ${ }^{32}$ Hegel denomina "astucia de la razón" al hecho de que los Estados, pueblos e individuos, descansando en sus principios particulares y obedeciendo a sus propios intereses y pasiones, funcionan sin embargo como instrumentos inconscientes del espíritu universal, ejecutando el proyecto de la razón y siguiendo los estadios que éste planifica. ${ }^{33}$ El espíritu universal se encarnaría sucesivamente en diferentes pueblos, que constituirían estadios de su desarrollo y su saber, y que devendrían dominantes en la historia durante ese período y sólo ese período. Sin embargo, para Hegel un pueblo sólo adquiere una existencia universal y universalmente válida al

\footnotetext{
${ }^{32}$ Ibid., 791, $\$ 342$.

${ }^{33} \mathrm{La}$ "astucia de la razón" hegeliana como motor "natural" del acaecer histórico, puede compararse con la "insociable sociabilidad" de Kant y con el principio liberal de la "mano invisible", donde la persecución de los intereses particulares tiene como resultado espontáneo el bienestar general.
} 
constituirse como Estado soberano y dotarse de leyes propias, y sólo tiene relevancia desde el punto de vista histórico cuando crea una nuevo principio o versión de la libertad. ${ }^{34}$

El comienzo de la "historia real" de la humanidad ocurre para el filósofo con el surgimiento del Estado a partir del matrimonio y de la agricultura, ${ }^{35}$ es decir, cuando el hombre deja de estar completamente sometido a la naturaleza y comienza a liberarse el espíritu que se manifiesta en el arte, en la religión y en el pensamiento filosófico. Los distintos momentos en la historia universal -protagonizados por distintos "reinos" o "imperios" asentados sobre principios diferentes- son distintos momentos en el desarrollo de la idea del Estado (o sustancia ética) y de la libertad que allí se realiza.

El universal abstracto en este desarrollo es el espíritu "sustancial inmediato", principio que está representado por los Estados teocráticos orientales. Es el Estado como una totalidad indivisa y natural, en cuya esencia se encuentra hundido el individuo, que carece de fundamento y de derechos, y donde el único hombre libre es el déspota o patriarca. El segundo momento es el "saber de este espíritu sustancial [...] y el ser para sí en cuanto forma viviente del mismo, la bella individualidad ética", ${ }^{36}$ representado por el mundo griego. Es el Estado que se sabe producto de la voluntad y la actividad humanas y que se esclarece como tal en el propio desarrollo de la vida ética intersubjetiva. Aquí surge el principio de la personalidad individual, pero todavía no se afirma en la autoconsciencia subjetiva sino en la totalidad, en "una fuerza que estaría más elevada y fuera de esa misma autoconsciencia". ${ }^{37}$ En esta configuración del Estado, sólo son libres sus miembros -es decir, los ciudadanos- y se encuentran excluidos los esclavos. El tercer estadio constituye una profundización del segundo, donde se produce una afirmación "en-sí" del individuo y "un desgarramiento infinito de la vida ética en los extremos de la autoconciencia personal privada y la universalidad abstracta". ${ }^{38}$ Es el principio expresado por el imperio romano, donde se produce la muerte de la vida ética, donde los individuos devienen personas privadas unidas abstractamente por el derecho formal y donde priman los intereses y pasiones particulares. Finalmente, el cuarto momento constituye la superación de la oposición entre el universal y el particular y su reconciliación "como pensamiento y como mundo de realidad legal". 39 Es la idea que para Hegel encarna el Estado moderno, al que denomina "cristiano-germánico", ya que sería el emergente de la lucha y reconciliación de los principios distintivos del pueblo israelita y del pueblo germánico. El Estado constitucional moderno es aquel donde se realizan verdaderamente la razón y la libertad, donde se produce la unidad entre la libertad objetiva y subjetiva, y donde la totalidad de sus miembros son libres. Es allí donde el sujeto individual está en condiciones de desenvolver

\footnotetext{
${ }^{34}$ Por este motivo, los pueblos de América -especialmente de América Latina- quedan en el planteo hegeliano por fuera de la historia universal, debido a su condición semi-colonial y relativamente atrasada con respecto a las metrópolis europeas.

${ }^{35}$ Hegel, op.cit., 797, §353.

${ }^{36}$ Idem.

${ }^{37}$ Ibid., 800, §356

38 Ibid., \$357.

${ }^{39}$ Ibid., 797, §353.
} 
su particularidad y autenticidad y donde el espíritu universal encuentra el terreno fértil para desplegarse a sus anchas. Y también es el ámbito donde el espíritu y la libertad devienen plenamente autoconscientes, sabiéndose como el resultado de un proceso históricouniversal de emancipación y queriéndose libres precisamente porque se saben como una conquista histórica de la humanidad. Como se puede advertir, el proceso de liberación al que se refiere Hegel encuentra su punto culminante en la revolución burguesa, lo cual no es un detalle menor, porque implica que la libertad-consciente-de-sí, esta forma suprema de libertad, sólo ha podido alanzarse en la modernidad.

\section{La libertad según Marx}

\section{La crítica de la filosofía hegeliana del derecho}

Como se sabe, antes de volcarse al comunismo y convertirse en uno de sus referentes más importantes, Marx formaba parte de la izquierda hegeliana y era partidario de la fundación de una república democrática en Alemania. Sus primeros cuestionamientos a la filosofía del derecho de Hegel apuntaban principalmente contra su defensa de la monarquía constitucional y otros resabios pre-modernos, y bregaban por una transformación todavía más profunda. Durante este período, su concepción de la libertad no trascendía los márgenes de la teoría política anterior, que veía al Estado como el ámbito propicio para su desenvolvimiento, pero impulsaba su organización republicana y democrática, que era la forma estatal más radicalizada y acabada que había concebido la burguesía. Independientemente de la importancia que esta idea de la libertad pueda tener en la trayectoria intelectual y política del propio Marx, aquí sólo se hará referencia a su ruptura con ella y a su elaboración de otra nueva, que es la que permite entenderlo no sólo como un heredero radical del pensamiento político hegeliano (y moderno en general) sino también como una superación de éste.

El punto de inflexión en su perspectiva puede ser ubicado alrededor de 1843, con la redacción de La cuestión judía y de la Introducción a la crítica de la filosofía del derecho de Hegel, textos en los que delinea su crítica del Estado moderno, caracterizándolo como una forma "profana" de alienación, y en los que señala las limitaciones de la revolución burguesa. A contramano de Hegel, Marx plantea allí que en el Estado moderno -incluso en la república democrática-, no se resuelve el desgarramiento entre los intereses particulares y universales vigente en la sociedad civil. "El Estado moderno hace abstracción del hombre real o bien provee al hombre total de una satisfacción imaginaria". ${ }^{40}$ Lejos de producir una conciliación entre el bourgeois y el citoyen, el Estado reafirma su escisión y el hombre lleva, no sólo en su conciencia sino en la realidad, una doble vida: "una celestial y otra terrenal; la vida en la comunidad política en la que se considera ser colectivo y la vida en la sociedad civil en la que actúa como hombre privado, considera los demás simples medios,

\footnotetext{
${ }^{40}$ Karl Marx, Crítica de la filosofía del derecho de Hegel, Buenos Aires, Del signo, 2005 [1843], 61.
} 
se degrada a sí mismo al papel de simple mediador y se convierte en juguete de fuerzas extrañas". 41 El Estado moderno aparece como una comunidad "ideal" separada y contrapuesta a la realidad "material" de la sociedad civil. Aunque él proclame principios universales como la libertad, la igualdad y la fraternidad ello no impide que la dominación, la desigualdad y los antagonismos sociales continúen existiendo en la sociedad civil. Marx critica la idea del contrato social y los droits de l'homme de la Revolución Francesa planteando que identifican al hombre con el burgués, con el individuo egoísta replegado sobre sí mismo, y que en vez de considerarlo como un ser social, presentan la propia vida en sociedad como un marco externo y una limitación de su supuesta autonomía originaria. El Estado moderno no es entonces la realidad de la razón y de la libertad como para Hegel, sino una expresión de la enajenación y la opresión humanas. La libertad y el interés general se manifiestan en él de manera formal y abstracta, pero no tienen un correlato en la vida colectiva real de los hombres. Es aquí donde Marx advierte los límites de la revolución burguesa.

Indudablemente, el derrocamiento del Antiguo Régimen y la destrucción de la sociedad feudal significaron un enorme progreso para la humanidad. Al barrer con la dominación fundada en lazos personales, la revolución burguesa liberó a la sociedad de las ataduras políticas que la constreñían y la disolvió en los individuos que la integraban. También liberó el espíritu político, convirtiendo los asuntos del Estado que antes concernían a unos pocos, en asuntos del pueblo en su conjunto. Sin embargo, ella no emancipó a toda la sociedad sino solamente a una parte, erigiéndola como clase dominante. No eliminó la dominación como tal, la sustituyó por otra nueva, y por eso se trata de una revolución "parcial" o meramente "política". ${ }^{2}$ En consecuencia, Marx plantea la necesidad de una emancipación "social" o "humana" que transforme de raíz la sociedad, removiendo las bases de toda forma de dominación y enajenación. ${ }^{43}$

¿Pero en qué consiste su idea de la libertad y en dónde radica su herencia y su novedad con respecto a la teoría política anterior, especialmente la de Hegel? Marx es sin dudas un heredero radical de la libertad liberal, ya que su obra puede leerse como una teoría y una justificación de la revolución, es decir, de la libertad como liberación. Asimismo, el vínculo entre trabajo y libertad adquiere en su pensamiento su elaboración más acabada, mediante el ideal de un trabajo autónomo y de un creciente desarrollo del tiempo libre. ${ }^{44}$

\footnotetext{
${ }^{41}$ Karl Marx, Sobre la cuestión judía, Buenos Aires, Prometeo, 2004 [1844], 19.

42 “Sobre qué descansa una revolución parcial, únicamente política? Sobre el hecho de que una parte de la sociedad civil se emancipe y logre la dominación general de la sociedad, partiendo de su situación particular". Karl Marx, Crítica de la filosofía del derecho de Hegel, Buenos Aires, Del signo, 2005 [1843], 67.

${ }^{43}$ Ya en este planteo temprano, queda claro que para Marx la clave de lo político hay que buscarla en lo social y no al revés.

${ }^{44}$ Distintos autores se han abocado al problema del tiempo libre en el pensamiento de Marx, destacándose entre estos los referentes de la escuela de Frankfurt. Aunque se trata de una dimensión importante en la concepción marxista de la libertad, aquí no se profundizará en ella porque es un aspecto que el autor desarrolla sobre todo en sus escritos de madurez (especialmente, en los Grundrisse y en El Capital), mientras
} 
Finalmente, debido a su carácter revolucionario, la teoría marxista implica una defensa a ultranza de la libertad negativa frente al poder estatal, ya que no hay nadie más interesado en resguardar el libre pensamiento, la libre expresión y la vida privada de los individuos frente a la vigilancia y la intervención del Estado, que quienes buscan derribar el orden existente y erigir una nueva sociedad. Marx también es un heredero radical de la libertad entendida como autonomía, ya que en los esbozos que realiza sobre cómo sería la organización del trabajo y los asuntos públicos bajo la sociedad comunista, se encuentra una refinadísima recepción de los principios de autodeterminación y autogobierno. Y Marx es, sobre todo, un heredero radical de las ideas que Hegel tiene sobre la libertad. Además de los ejes comunes señalados al comienzo de este artículo, en su pensamiento se puede advertir una recuperación de la libertad-consciente-de-sí, puesto que el comunismo y la libertad que allí se alcanza se auto-comprenden como el resultado de una emancipación práctica, como una conquista social e histórica nacida de la revolución.

\section{El materialismo histórico}

Ahora bien, para entender la originalidad y la dimensión superadora del enfoque marxista sobre la libertad, es necesario enmarcarlo en la concepción materialista de la historia, que Marx y Engels elaboraron en contraposición a la filosofía hegeliana y neohegeliana. A diferencia del materialismo anterior que abordaba la realidad como un objeto dado y ajeno a la voluntad, esta concepción recupera el punto de vista subjetivo del idealismo, entendiéndola como "actividad humana sensorial" 45 y se vale del método dialéctico para captarla en su movimiento y desarrollo. Pero a contramano de Hegel, coloca la dialéctica de manera invertida, partiendo de las condiciones de existencia objetivadas y materializadas, para dar cuenta de las manifestaciones espirituales e ideales. Su premisa no es un "sujeto" activo y pensante pero al mismo tiempo separado de la práctica real (como en Hegel), ni tampoco el "ser humano" sensible pero entendido de manera a-histórica y esencialista (como en Feuerbach). Su punto de partida son los hombres reales, tal como viven y se reproducen cotidianamente, y concebidos en sus múltiples dimensiones y relaciones constitutivas. Desde esta perspectiva, el hombre real es un ser natural, que tiene necesidades que debe satisfacer para sobrevivir; es un ser social, que vive y se desarrolla junto con otros hombres; y es un ser consciente, capaz de volverse reflexivo sobre su propia práctica. Es un ser condicionado por las circunstancias históricas y al mismo tiempo activo, ya que puede transformar esas circunstancias mediante su acción, siendo el trabajo su actividad transformadora por excelencia. De este modo, la idea hegeliana del sujeto como un ser teórico, práctico y productivo queda aquí reformulada mediante su vinculación al hombre histórico concreto.

que aquí el interés se concentra en sus textos juveniles, marcados fuertemente por la polémica con Hegel y los neohegelianos.

${ }^{45}$ Karl Marx, “Tesis sobre Feuerbach”, Marx, Karl y Engels, Friedrich, La ideología alemana, Buenos Aires, Santiago Rueda, 2005 [1845], 665.

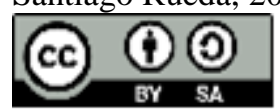


Como ha sugerido Jürgen Habermas, el materialismo histórico pretende conciliar la teoría darwiniana de la evolución con una teoría del desarrollo social del hombre, reconstruyendo la historia de la especie mediante una sucesión lógica de "modos de producción", es decir, partiendo de las formas que ha asumido históricamente el trabajo social del ser humano. ${ }^{46}$ Al mismo tiempo, se trata de una teoría "crítica y revolucionaria" porque investiga las condiciones de posibilidad de lo existente, pero descubre en ellas también las condiciones de su negación y superación, ${ }^{47}$ porque se propone son sólo conocer el mundo sino también transformarlo. ${ }^{48}$ Sintéticamente, su abordaje de las formaciones sociales plantea que las relaciones que los hombres entablan entre sí están condicionadas por el modo en que se vinculan con la naturaleza para reproducir su vida material. A determinado grado de desarrollo de las fuerzas productivas, corresponden determinadas relaciones sociales de producción, y ambas constituyen el fundamento económico que condiciona (de manera compleja y decididamente no determinista) las ideas, las formas de Estado, la política, la moral, la religión que existen en esa sociedad. Cuando en un modo de producción particular el desenvolvimiento de las fuerzas productivas alcanza un cierto nivel, entra en contradicción con las relaciones de producción existentes y se abre entonces un período de cambio social. $^{49}$

\section{Estado, historia y emancipación}

Marx y Engels sientan las bases de esta perspectiva teórica en La ideología alemana que, desde la óptica de este trabajo, constituye un texto fundamental puesto que en él se expresa una nueva toma de distancia de la filosofía del derecho hegeliana y también se condensan las líneas fundamentales de la concepción marxista de la libertad. Los autores se refieren aquí a las razones históricas del surgimiento y perdurabilidad del Estado, y ya no critican sólo su forma moderna, sino también sus formas anteriores. El Estado es caracterizado como el resultado histórico de la división del trabajo y del surgimiento de las clases sociales. Es el emergente de la división entre el trabajo físico e intelectual, de que la sociedad se fragmenta entre quienes viven de su propio trabajo y quienes viven del trabajo ajeno, y por eso pueden dedicarse a otro tipo de actividades como la política, la religión o el conocimiento. La aparición de las clases se vio impulsada por un salto cualitativo en el desarrollo de las fuerzas productivas a partir del dominio de la ganadería y la agricultura, que dio lugar a un excedente en la producción social, permitiendo que algunos individuos se liberaran de la necesidad de producir para sobrevivir y se apropiasen del trabajo de otros. El Estado expresa esta desigualdad estructural en la sociedad, donde la clase propietaria domina a la que no lo es, y cuya propiedad es tanto el resultado como la condición para la

\footnotetext{
46 Jürgen Habermas, "Para la reconstrucción del materialismo histórico”, Cuadernos políticos, 28, $1981,12$.

${ }^{47}$ Marx, Karl, El capital. Crítica de la economía política, Libro I-Tomo I, Madrid, Akal, 2000 [1867], 30.

${ }^{48}$ Karl Marx, “Tesis sobre Feuerbach”, Marx, Karl y Engels, Friedrich, La ideología alemana, Buenos Aires, Santiago Rueda, 2005 [1845], 668.

${ }^{49}$ Marx, Karl, "Prólogo", Contribución a la crítica de la economía política, México, Siglo XXI, 2008 [1859], 4-5.
} 
expropiación de ésta. A contramano de quienes sostienen que para Marx el Estado es un mero aparato de represión, aquí se enfatiza en su papel ideológico. Toda clase que aspire a convertirse en clase dominante, deberá tomar el poder político para poder presentar su propio interés como el interés general de la sociedad. El Estado es un factor de ocultamiento de las desigualdades y antagonismos sociales, porque aparece como la encarnación del bien común, cuando en realidad es el garante del interés particular de la clase dominante y el recurso fundamental que ésta utiliza para perpetuar su dominación. ${ }^{50}$

A lo largo de la historia universal se han desplegado distintos modos de producción caracterizados por distintos niveles de desarrollo de las fuerzas productivas, distintas relaciones sociales y distintas formas de propiedad, que constituyen el verdadero fundamento social de los tipos de Estado que describía Hegel y de la libertad que en ellos se manifestaba. Como señala Eric Hobsbawm, aunque Marx presenta los diferentes modos de producción como estadios históricos sucesivos, se trata de una sucesión lógica no cronológica. Las formaciones "asiática", "antigua", "feudal" y "capitalista" son progresivas en el sentido de que cada una representa un momento evolutivo posterior con respecto a la situación originaria del hombre en el "comunismo primitivo", marcado por la unidad entre trabajo y propiedad y entre individuo y comunidad. Cada una expresa un grado mayor en el desenvolvimiento de la propiedad privada y la individualización del ser humano, desarrollo en el que el capitalismo implica un salto cualitativo. ${ }^{51}$ El comunismo primitivo basado en relaciones igualitarias y en la propiedad comunal, es anterior al dominio de la agricultura y al surgimiento de las clases y el Estado, razón por la cual este período no está contemplado en la filosofía histórica hegeliana. Los modos de producción asiático, antiguo, feudal y capitalista son sociedades estratificadas o clasistas, donde existe una determinada organización estatal para garantizar la dominación de unos hombres por otros.

A contramano de la lógica racional que Hegel advertía en la historia, Marx y Engels remarcan el carácter "natural" e impuesto que ha tenido el desenvolvimiento de la división del trabajo, generando que las fuerzas y relaciones entre los hombres nacidas de su cooperación en el trabajo social, se les hayan enfrentado hasta el momento como un poder ajeno y hostil. ${ }^{52}$ Extendiendo la idea de alienación que Marx había aplicado a la sociedad capitalista $^{53}$ a todos los modos de producción anteriores, remarcan que hasta ahora la producción ha estado por fuera del control consciente de los hombres y su organización

\footnotetext{
${ }^{50}$ Esta es la idea que Marx y Engels desarrollarán luego en el Manifiesto Comunista, donde plantean que el Estado es la violencia organizada de una clase para la opresión de otra, que se despliega tanto coercitivamente (mediante la acción de los aparatos represivos) como simbólicamente (mediante la ideología expresada en las leyes, la educación, la religión, etc.). Karl Marx y Friedrich Engels, Manifiesto Comunista, Buenos Aires, Catari, 1994 [1848], 54.

${ }^{51}$ Eric Hobsbawm, "Introducción”, Marx, Karl, Formaciones económicas precapitalistas, México, Siglo XXI, $2004,35$.

${ }^{52}$ Karl Marx y Friedrich Engels, La ideología alemana, Buenos Aires, Santiago Rueda, 2005 [1845], 34.

${ }^{53}$ En los Manuscritos económico-filosóficos de 1844, Marx retoma la noción hegeliana de la alienación para referirse al trabajo asalariado. Allí distingue tres dimensiones del trabajo alienado: con respecto al producto, con respecto al propio trabajo como actividad humana y con respecto a la especie y a los demás hombres. Karl Marx, Manuscritos económico-filosóficos de 1844, Buenos Aires, Colihue, 2004 [1844], 107-114.
} 
social se ha configurado al margen de su voluntad. Y precisamente por este carácter involuntario y desigual de la división del trabajo, surgió el antagonismo entre los intereses particulares de los individuos y las clases y el interés general de la comunidad, y se hizo necesario el Estado como una instancia exterior e independiente que busca conciliarlos y representar lo común. En efecto, Marx y Engels plantean que

Esta consolidación de nuestros propios productos en un poder material erigido sobre nosotros, sustraído a nuestro control [...] es uno de los momentos fundamentales que se destacan en todo el desarrollo histórico anterior y precisamente por virtud de esta contradicción entre el interés particular y el interés común, cobra el interés común, en cuanto Estado, una forma propia e independiente, separada de los reales intereses particulares y colectivos $\mathrm{y}$, al mismo tiempo, como una comunidad ilusoria, pero siempre sobre la base real de los vínculos existentes [...] y, sobre todo, $[\ldots]$ a base de las clases [...] entre las cuales hay una que domina a las demás. ${ }^{54}$

Asimismo,

En los sustitutivos de la comunidad que hasta ahora han existido, en el Estado, etc., la libertad personal sólo existía para los individuos desarrollados dentro de las relaciones de la clase dominante y sólo tratándose de individuos de esta clase. La aparente comunidad en que se han asociado hasta ahora los individuos ha cobrado siempre una existencia propia e independiente frente a ellos $\mathrm{y}$, por tratarse de una asociación de una clase en contra de otra, no sólo era [...] una comunidad puramente ilusoria para la clase dominada, sino también una nueva traba. La relación de comunidad en que entran los individuos de una clase, relación condicionada por sus intereses comunes frente a un tercero, era siempre una comunidad a la que pertenecían [...] solamente como individuos medios [...] es decir, una relación que no los unía en cuanto tales individuos, sino en cuanto miembros de una clase. ${ }^{55}$

Así, a diferencia de lo que planteaba Hegel, el Estado es una comunidad puramente aparente que no supera sino que refleja la escisión vigente al interior de la sociedad. Él no encarna la "voluntad sustancial" de la colectividad, sino que expresa la libertad alcanzada por los miembros de la clase dominante, la cual se basa en la opresión de la clase laboriosa que encuentra en el Estado una comunión ilusoria con sus explotadores y un obstáculo decisivo para su propia libertad. Al mismo tiempo, la organización estatal no permite el pleno desenvolvimiento de la particularidad del sujeto porque es la contracara de la existencia de las clases, y las relaciones sociales mediadas por las clases, dan como

\footnotetext{
${ }^{54}$ Marx y Engels, op. cit., 35.

${ }^{55}$ Ibid., 87.

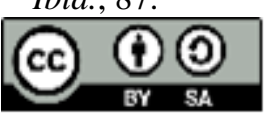


resultado tan sólo "individuos medios". Es decir, individuos que están condicionados por las circunstancias en las que les ha tocado nacer y desarrollarse, y que se relacionan con los demás constreñidos por esos condicionamientos sociales que obstaculizan un despliegue verdaderamente libre y voluntario de la propia subjetividad. En consecuencia, aunque los miembros de la clase dominante gocen de un grado mayor de libertad que los de la clase oprimida, tampoco son real y completamente libres, porque dependen de ésta para existir como tales y porque su subjetividad también está moldeada por esa relación de dominación. Como se desprende de esto, el planteo marxista de eliminar las clases no está determinado, como a veces se sostiene, por su voluntad de hundir al individuo en un igualitarismo amorfo y primitivo, similar al comunismo pre-moderno que Marx le atribuye a Platón en sus Manuscritos económico-filosóficos de 1844. Por el contrario, el autor concibe la igualdad como una condición indispensable para el verdadero desarrollo de la individualidad.

En resumen, y en abierta ruptura con Hegel, para Marx el Estado no es el ámbito que permite el pleno desenvolvimiento de la libertad y del sujeto, sino que existe precisamente porque la sociedad y los hombres no son libres; porque la sociedad se encuentra dividida en clases con intereses contrapuestos; y porque los hombres no desarrollan voluntariamente su actividad humana por excelencia, que es el trabajo con el que crean su mundo material y espiritual. El Estado salvaguarda la dominación de clase, en consecuencia, la historia de sus diferentes principios no podría constituir como en Hegel la historia universal de la libertad, sino tan sólo su "prehistoria", donde el hombre no se ha emancipado completamente de la naturaleza y se desarrolla en el marco de relaciones independientes de su voluntad. Para Marx, la verdadera historia de la humanidad sólo comenzará con la eliminación de las clases, del Estado y de la sujeción del hombre a la naturaleza, mediante el establecimiento del comunismo a escalas planetarias, porque sólo a partir de entonces podrá hablarse con propiedad de una sociedad libre y de individuos libres, es decir, de una libertad "humana" en el auténtico sentido de la palabra.

El desarrollo histórico de distintos modos de producción descripto por el autor, debe interpretarse entonces como el lento proceso de emancipación de la humanidad de la necesidad natural y de los vínculos sociales opresivos. Se trata de un proceso históricouniversal pero que, a diferencia de Hegel, no se despliega de manera teleológica y necesariamente progresiva. Su motor fundamental es la lucha de clases, que tiene momentos de avance y de retroceso, y así como la humanidad puede dar un salto cualitativo en su libertad, también puede hundirse en la barbarie. Siguiendo a István Mészáros, es posible sostener que los distintos modos de producción generan las condiciones y constituyen distintos momentos en el desenvolvimiento de la libertad, en al menos tres dimensiones: en relación a la naturaleza, en el marco de las relaciones sociales y en el plano individual. ${ }^{56}$ En efecto, el grado de desarrollo alcanzado por las fuerzas productivas, expresa asimismo el grado en que los hombres se han emancipado de la necesidad natural mediante su trabajo. Esta relación con la naturaleza condiciona, a su vez, el tipo de vínculo

\footnotetext{
${ }^{56}$ István Mészáros, La teoría de la enajenación en Marx, México, Era, 1978, 143-144. 
que ellos entablan entre sí y, junto con éste, los grados de libertad existentes en las relaciones de unos hombres con otros. Finalmente, el tipo de relaciones sociales vigentes, condiciona la libertad que los individuos tienen para ejercer sus propias capacidades y potencialidades subjetivas.

Cuando los hombres tienen un vínculo inmediato y primitivo con la naturaleza, las relaciones que entablan entre sí también son elementales. Marx constata que hubo un largo período de la historia (el comunismo primitivo), en el que los seres humanos estaban totalmente sometidos a aquélla y, en consecuencia, no se puede hablar con propiedad de la existencia de la libertad. Pero esto fue modificándose a medida que las fuerzas productivas se fueron desarrollando. La llamada revolución neolítica y el excedente en la producción social que ella trajo aparejado, implicaron un salto cualitativo para la humanidad. Como se dijo antes, desde ese momento surgen la propiedad privada y las sociedades organizadas en clases sociales, en donde la clase propietaria se ha emancipado de la necesidad de producir y vive del trabajo ajeno; y surge también el Estado como órgano destinado a la reproducción del orden social.

Evidentemente, los grados de libertad vigentes en el marco de las relaciones clasistas han sido diversos: en principio, las relaciones serviles de la Edad Media implicaron un avance con respecto al esclavismo de la Antigüedad, y la relación capitalista moderna, que disolvió los vínculos políticos y convirtió la explotación en algo estrictamente económico, un avance radical con respecto a estas últimas.

En cuanto al desarrollo de la libertad individual, se ha señalado que en los modos de producción que han existido hasta el momento, ésta ha sido el privilegio de la clase dominante. Habiéndose liberado de la necesidad de trabajar para sobrevivir, la clase dominante puede dedicarse a otras actividades y a cultivar su personalidad. Por el contrario, la clase oprimida obligada a producir casi no tiene espacio para el ocio y el disfrute personales. La libertad de la clase dominante está indisociablemente unida a su control del Estado y a su participación en los asuntos públicos. El ejercicio de los derechos políticos siempre estuvo restringido a quienes poseían propiedad privada. Sólo en la sociedad moderna, donde la dominación política de la burguesía se realiza de manera indirecta, mediante funcionarios que gobiernan representando sus intereses, la ciudadanía se extiende al conjunto de la nación. Sin embargo, el pleno desarrollo de la libertad subjetiva sólo será posible por fuera de las relaciones de clase.

\section{El comunismo como asociación libre de individuos libres}

El carácter novedoso y superador de la concepción marxista de la libertad emerge precisamente de su crítica del Estado como órgano de dominación social y de su consideración histórica del desarrollo concreto de la emancipación del hombre a lo largo de los distintos modos de producción. Es a partir de esto que Marx está en condiciones de plantear una versión original de la libertad, que trasciende los límites de la ciudadanía política y concibe como auténticamente social o "humana".

En efecto, frente a la libertad vinculada al Estado y restringida a los miembros de la clase dominante, Marx plantea al comunismo como el ámbito que permitiría el 
desenvolvimiento de una libertad de alcance universal, que se materializaría realmente en la vida social superando la alienación precedente y permitiendo el pleno desarrollo de las cualidades y potencialidades subjetivas. De manera que, pensar las condiciones de posibilidad de esta libertad implica volverse reflexivo sobre las "premisas prácticas" del comunismo, que para Marx y Engels se han desarrollado al interior del modo de producción capitalista. ${ }^{57}$ En primer lugar, es necesario el surgimiento de una clase revolucionaria que busque derribar el orden existente y reestructurar la sociedad sobre nuevas bases. El proletariado encarna el sujeto revolucionario por ser una clase completamente desposeída y continuamente degradada que, para realizar su propio interés y emanciparse a sí misma, debe eliminar la propiedad privada e impulsar una organización colectiva de la producción social. En segundo lugar, es necesario que las fuerzas productivas se hayan desarrollado en un alto grado y en un plano histórico-universal. De este modo, la transformación humana de la naturaleza se habrá desenvuelto hasta tal punto que permitirá una superación de la escasez y se podrá proceder a una socialización de la riqueza y no de la miseria. Por otra parte, los intercambios y la dependencia mutua de los individuos en el trabajo social se habrán extendido a nivel mundial, y el proletariado se habrá constituido en los distintos países, permitiendo con ello que la revolución tenga un carácter universal. A estas dos condiciones, hay que agregar la tercera y quizás más importante: el movimiento práctico que derribe el poder político y erija al proletariado en clase dominante en los distintos países, quien deberá motorizar las transformaciones necesarias para llegar a una sociedad sin clases y sin opresión. En este sentido, la revolución social constituye un verdadero acto de libertad.

De la consideración de estas premisas se desprende que el comunismo y la emancipación de la humanidad no constituyen para Marx una mera utopía. El capitalismo ha generado las condiciones materiales de su propia superación y de una forma más acabada de libertad que no podría haberse alcanzado en períodos anteriores, cuando el hombre estaba todavía sometido a los azares de la naturaleza y la escasez era una amenaza real para éste.

Solamente dentro de la comunidad con otros tiene todo individuo los medios necesarios para desarrollar sus dotes en todos los sentidos, solamente dentro de la comunidad es posible, por tanto, la libertad personal. [...] Dentro de la comunidad real y verdadera, los individuos adquieren al mismo tiempo su libertad al asociarse y por medio de la asociación.

(En) la comunidad de los proletarios revolucionarios, que toman bajo su control sus condiciones de existencia y las de todos los miembros de la sociedad [...] toman parte los individuos en cuanto individuos. Esta comunidad no es otra cosa [...] que la asociación de los individuos (partiendo, naturalmente, de la premisa de las fuerzas productivas tal y como ahora se han desarrollado), que entrega a su control las condiciones

\footnotetext{
${ }^{57}$ Marx y Engels, op. cit., 36-38. 
del libre desarrollo y movimiento de los individuos, condiciones que hasta ahora se hallaban a merced del azar y habían cobrado existencia propia e independiente. ${ }^{58}$

Se evidencia aquí la herencia rousseauniana y hegeliana de que sólo en el marco de una comunidad con otros y asociándose completamente, adquiere el individuo su propia libertad. Pero para Marx la comunidad real y verdadera donde se alcanza efectivamente la libertada colectiva, permitiendo al mismo tiempo el pleno desarrollo del sujeto y de la libertad individual, no es el Estado sino la sociedad comunista. Es allí donde se produce realmente la reconciliación de los intereses universales y particulares. El comunismo se distingue de todos los modos de producción anteriores porque elimina de raíz la forma en que la actividad productiva y la sociedad han venido desarrollándose, abordándolas por primera vez de manera consciente y voluntaria. La revolución proletaria eliminará la propiedad privada y llevará a cabo una apropiación social de las fuerzas productivas nacidas de la cooperación entre los hombres, que hasta ahora se enfrentaban a éstos como un poder material ajeno e independiente, superando así la alienación y permitiendo que los hombres recuperan conscientemente sus relaciones constitutivas: con la naturaleza, con el trabajo como actividad social y con los otros hombres como sujetos. Es aquí donde se afirman conscientemente en su carácter multidimensional y donde las capacidades humanas (tanto sociales como individuales) alcanzan su pleno desenvolvimiento.

Debido al carácter internacional de la división del trabajo, la apropiación y asociación deberán tener un alcance no sólo local, sino también universal. La revolución eliminará la división forzosa del trabajo y someterá la producción a una planificación y control colectivos de la comunidad. Con ello, no sólo barrerá con la vieja sociedad, sino que generará las condiciones de una nueva asociación: las relaciones sociales dejarán de tener un carácter necesario, las clases sociales se extinguirán y, con la superación de la opresión social, el Estado perderá su razón de ser. La sociedad dejará de ser una sociedad "natural" para convertirse en una "asociación libre, de individuos libres", donde los individuos que se relacionan entre sí sin ninguna otra mediación que su condición de individuos, y donde el libre desarrollo de cada uno se complementa y amplía con el de los demás. Sólo bajo los términos de esta nueva asociación, será posible el pleno desarrollo de la libertad y las capacidades individuales.

Retomando a Saint-Simon, Marx concibió el comunismo como el tránsito “del reino de la necesidad al reino de la libertad". Luego de todo lo dicho, es posible apreciar el sentido profundo de esta afirmación. El comunismo constituye el verdadero reino de la libertad, porque permitiría a los hombres emanciparse finalmente de la necesidad natural y de las relaciones forzosas impuestas en el pasado por el escaso desarrollo de las fuerzas productivas, para alcanzar una libertad auténticamente "humana": una libertad de los hombres en cuanto hombres y de alcance plenamente universal.

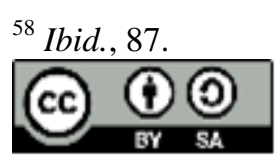




\section{Reflexiones finales}

A lo largo de estas páginas se ha realizado una comparación entre las concepciones de la libertad de Hegel y Marx, indagando continuidades y rupturas entre ambas. También se ha interpretado la perspectiva marxista de la libertad como heredera y superadora de la hegeliana, y se espera haber abonado la tesis de que no se puede comprender acabadamente a Marx dejando de lado sus escritos juveniles en los que entabla un diálogo permanente con la filosofía de Hegel, y constituye una verdadera tergiversación de su pensamiento el intento estructuralista de cercenar esa parte de su obra.

Desde la óptica de este trabajo, tanto Hegel como Marx deben ser considerados como dos grandes teóricos de la emancipación humana, que pensaron lúcidamente el problema de la libertad desde circunstancias históricas disímiles y tuvieron ideas de avanzada en el marco de esas circunstancias. Si el planteo de Marx representa una superación con respecto al de Hegel, no es porque este último sea un mero ideólogo del orden constituido, sino simplemente porque los poco más de veinte años que median entre los Fundamentos... y los textos marxianos, fueron años decisivos en el desarrollo del capitalismo y de la lucha de clases. La idea que Marx tiene sobre la libertad no podría haber sido pensada en el contexto semi-feudal en el que escribió Hegel. Aquí se han dejado deliberadamente de lado algunas partes importantes de su filosofía del derecho que han sido utilizadas para catalogar a Hegel de conservador o juzgarlo como un simple apologeta del Estado prusiano. Se trata de una lectura equivocada porque la defensa que el filósofo realiza del Estado de derecho y de la supremacía de la constitución, era completamente progresiva en el contexto reaccionario de la Restauración. Por lo demás, esta mirada sesgada queda desestimada si se tiene en cuenta quiénes fueron los que, tras la muerte de Hegel, se afanaron denodadamente por sepultar su pensamiento, y quiénes -como Marx y Engels- se reconocieron abiertamente como sus herederos.

A la luz del contexto actual, cuando el régimen capitalista y sus crisis cada vez más frecuentes amenazan con hundir a la humanidad en la miseria, en nuevas guerras y en una degradación social creciente, parece necesario reivindicar la perspectiva crítica de Hegel y Marx así como la vigencia del programa teórico y político de la libertad, del cual fueron dos grandes pilares. El año 2017, cuando se cumpla el centenario de la Revolución Rusa, quizá sea un escenario propicio no sólo para reabrir el debate y sacar conclusiones sobre esa experiencia histórica, sino también para reflexionar sobre el presente y los desafíos contemporáneos de las perspectivas emancipatorias.

\section{Bibliografía}

- Aristóteles, Política, México, Universidad Nacional Autónoma de México, 1963.

- Bobbio, Norberto, "Hegel y el iusnaturalismo", VV. AA., Estudios sobre la filosofía del derecho de Hegel, Madrid, Centro de Estudios Constitucionales, 1989, 377- 406.

- Dri, Rubén, La rosa en la cruz. La filosofía política hegeliana, Buenos Aires, Biblos, 2009.

- Duque, Félix, La Restauración. La escuela hegeliana y sus adversarios, Madrid, Akal, 1999. 
- Habermas, Jürgen, "Para la reconstrucción del materialismo histórico", Cuadernos políticos, 28, 1981, 4-34.

- Hegel, Georg Wilhelm Friedrich, Fundamentos de la filosofía del derecho, Madrid, Libertarias/Prodhufi, 1993 [1821].

- Hegel, Georg Wilhelm Friedrich, Fenomenología del espíritu, México, Fondo de Cultura Económica, 1973 [1807].

- Hegel, Georg Wilhelm Friedrich, Lecciones sobre la filosofía de la historia universal, Madrid, Alianza, 1989 [1833].

- Hobbes, Thomas, Elementos filosóficos. Del ciudadano, Buenos Aires, Hydra, 2010 [1642].

- Hobsbawm, Eric, "Introducción”, Marx, Karl, Formaciones económicas precapitalistas, México, Siglo XXI, 2004, 9-64.

- Kant, Immanuel, Fundamentación para una metafísica de las costumbres, Madrid, Alianza, 2002 [1785].

- Locke, John, Ensayo sobre el gobierno civil, Buenos Aires, Universidad Nacional de Quilmes Prometeo, 2005 [1690].

- Marcuse, Herbert, Razón y revolución. Hegel y el surgimiento de la teoría social, Barcelona, Altaza, 1999.

- Marx, Karl, El capital. Crítica de la economía política, Libro I-Tomo I, Madrid, Akal, 2000 [1867].

- Marx, Karl, Manuscritos económico-filosóficos de 1844, Buenos Aires, Colihue, 2004 [1844].

- Marx, Karl, Sobre la cuestión judía, Buenos Aires, Prometeo, 2004 [1844].

- Marx, Karl, Crítica de la filosofía del derecho de Hegel, Buenos Aires, Del signo, 2005 [1843].

- Marx, Karl, "Tesis sobre Feuerbach”, Marx, Karl y Engels, Friedrich, La ideología alemana, Buenos Aires, Santiago Rueda, 2005 [1845], 665-668.

- Marx, Karl, "Prólogo", Contribución a la crítica de la economía política, México, Siglo XXI, 2008 [1859], 3-7.

- Marx, Karl y Engels, Friedrich, Manifiesto Comunista, Buenos Aires, Catari, 1994 [1848].

- Marx, Karl y Engels, Friedrich, La ideología alemana, Buenos Aires, Santiago Rueda, 2005 [1845].

- Mészáros, István, La teoría de la enajenación en Marx, México, Era, 1978.

- Rousseau, Jean-Jacques, El contrato social, Madrid, Alianza, 2012 [1762].

- Weil, Eric, Hegel y el Estado, Córdoba, Nagelkop, 1970.

- De Zan, Julio, "Para leer la filosofía del derecho de Hegel", Tópicos, 18, 2009. Recuperado de http://www.redalyc.org/articulo.oa?id=28815533003 